\title{
Stories Notebook about the Fundamental Concepts in Family Medicine: Comprehensiveness and Integrality, The Fable of The Tree and The Grass
}

\author{
Jose Luis Turabian
}

Health Center Santa Maria de Benquerencia Toledo, Spain

"Corresponding author: Jose Luis Turabian, Health Center Santa Maria de Benquerencia Toledo, Spain, Tel: 34925154508; Email: jturabianf@hotmail.com

Received date: January 10, 2017; Accepted date: January 25, 2017; Published date: February 01, 2017

Copyright: (c) 2017 Turabian JL. This is an openaccess article distributed under the terms of the Creative Commons Attribution License, which permits unrestricted use, distribution, and reproduction in any medium, provided the original author and source are credited.

\section{Introduction}

In this section of "Stories Notebook About The Fundamental Concepts In Family Medicine" you will learn the fundamental concepts of General Medicine/Family Medicine through stories or fables.

Conceptual systematization in the specialty of Family Medicine/ General Medicine has not matched with practice. However, it is not until that the conceptual heritage of Family Medicine, is ordered, systematized and fully clarified when it can begin the real practical work.

Therefore, it is necessary to achieve more meaningful representations of the fundamental concepts of Family Medicine, and facilitate the transfer of these to clinical practice $[1,2]$.

But, these concepts can be difficult to understand and explain, even for experienced physicians in the specialty. Thus, we propose the following concepts of Family Medicine/General Medicine, which we think are the main:

1. Comprehensiveness and integrality

2. Continuity

3. Context and contextualization

4. Uncertainty

5. Complexity

6. Community

7. Patientcentered Interview

8. Biopsicosocial Model

9. Actors and resources/strengths of the patients

10. Medicalization and technology

11. Family

12 Symptoms;

13. Diagnosis and treatment

14. Concept of health and disease

15. Variability

Evidence Based Medicine, clinical trials and quantitative studies are necessary, indispensable for medical science, yes, but why not the stories, the tales and the cases? So, we will be presented these concepts by fables.

The fable is an adult education method that can serve to intuitively understand abstract concepts by linking them to specific situations, for facilitating their assimilation. Animals, plants, minerals and other things will be "patients" seen in consultation by the family doctor [3-5].

They will be fictional stories presented as real. They will be beings or objects that are given the opportunity to think, feel and speak. In the fable it can be distinguished two parts: one is the story itself; and the other moral. Each story seeks to make emerge, of clear form, the moral, the end of the fable, as sobering consequence of what happened in the episode [6].

The moral will be a fundamental concept of Family Medicine/ General Medicine.

\section{Short Communication}

Once upon a time, a tree and some of grass that went to the doctor's office. The Mr. Tree was a plant of woody stem that branched to a certain height of the ground. He was in its ripe age and its height was of five meters, and he produced new secondary branches each year, giving rise to a new tree top separated from the ground.

"I feel sad, hopeless, immersed in melancholia for 3 weeks or so, without interest or pleasure in almost all activities, and that means I cannot with my social and work tasks, I have no energy, and I cannot do the daily tasks, and I do not sleep and I'm anxious, I have no appetite. I want to cry, I'm irritable, sad. Will I have something bad, Doctor? My head hurts, my bones, my guts "explained the Mr. Tree to the general practitioner".

The doctor, as he listened to him, was thinking, "Let's look at the hierarchical structure of the DSMIV classification". Each decision tree begins with a set of clinical characteristics and formulates a series of questions to confirm or rule out different diagnostic categories.

Is he depressed, with elevated, expansive or irritable mood because of the direct physiological effects of a medical illness?

Not seem. Is he so because of the direct physiological effects of a substance, such as a drug or a toxicant? No. Well, then, is he with high, expansive or irritable mood of at least 1 week of duration, with marked deterioration or hospitalization? No, Well, does he have a high mood, expansive or irritable, of at least 4 days of duration; changes observable by others, but less severe than those of a manic episode? Neither! Does he have at least 2 weeks of depressed mood or loss of interest, more associated symptoms, and that is not explained better by the presence of grief? Yes maybe so, that's it! It's a major depressive episode"!

Later, he consulted Mrs. Grass. She was a plant that had no woody organs, and which sprouted from subterranean stems located at ground level or rhizomes horizontally buried, that store reserves and out of them come shoots that form new plants (Figure 1). 


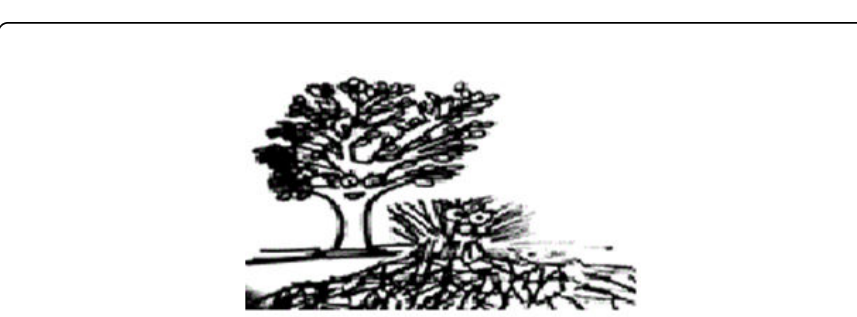

Figure 1: The Fable of The Tree and The Grass.

"Doctor, I had bladder cancer 2 months ago, and I have this stain on my eye will not it be a metastasis? And my heart failure is getting worse and my niece has to help me but I have much desire to live even if it increases my difficulty walking and I know that it is difficult to take care of me, that they are tired, besides these tremors and my forgetfulness Am I going crazy? When I am in the Day Care Center is something else, but I prefer my house and I know that recently I had to be entered in hospital by my heart but my niece has her family", explained Mrs. Grass.

"What's going on here?"!! The doctor asked himself in surprise. "I cannot apply a hierarchical tree of diagnostic, a hierarchy of patterns". There is a tangle of symptoms, full of ramifications, forming a tangled ball from which come and leave new symptoms that seem to neither begin nor end is a chaotic framework, which does not respond to any hierarchical order and, besides, with self-regeneration capacity: a problem is "solved" and reemerges or another appears. I cannot ask me a question to answer yes or no. So what is the main diagnosis? Where do I begin? Is it black or white? Is it singular or plural? : They are both"!

And the doctor, trying to calm himself, thought: "I see that the variables to consider are not linear, and if I try to follow a linear hierarchical tree course I can stay with irrelevant variables and have incomplete and erroneous data. For example, if I use the ejection fraction as the prognostic marker in your heart failure, and thus I have a hierarchy of values, I am simplifying the complexity. Thus, it would isolate one problem from others, impose a hierarchy of false intervention, and forget that there is a person whose heart has problems, like her whole body and her life. Each patient has a history and a meaning. How does live this person who suffers the limitations of their heart and their tremors, their forgetfulness and their worries, and the problems about the caregiver's overload? How is her despair? Can she build a project to overcome it?"

"I have to look at the case in a different way. Perhaps as did the impressionist painters of the nineteenth century when they looking at a landscape: collecting the objects not in their constancy, but according to the incidence of the environment; there are so many different landscapes in a same scenario as instants of the day. That is exactly the opposite of what is understood by "realism" that only attends on the object to its invariability, that is, that which does not contain the impact that the environment exerts on the object, so, it is an abstraction of the context".

And the doctor concluded: "The traditional approach of the scientist is an abstract solution an abstraction of the context, or a particular case of context. This approach is not correct. I have to focus the problem on the particular case, on the context, and it's transversely not in its objective abstraction. My knowledge of the case cannot be derived by the logical means from a set of quantitative data, but is elaborated simultaneously from all points under the reciprocal influence of the different observations and conceptualizations. My observation of the complaint, problem or illness must be made within the context of a patient with physical, emotional and social attributions that cannot be separated from each other".

For the family doctor, multimorbidity is important, yes it is, but the clinical concept of "rhizome" is not the presence of two or more diseases, not etiologically linked in the same individual, nor a set of risk factors, but it refers to being "between" the problems, in a third dimension: in the complexity of the framework of health disease phenomena, where each fragment can be read anywhere and put in relationship with any other [7]. The family doctor should use decentralized knowledge processes, without a single center, but that they are travelling from node to node. The family doctor should be a methodological opportunist in the sense that he is willing to go through various possible ways to achieve his goals in each particular situation.

\section{References}

1. Gannik DE (1995) Situational disease. Fam Pract 12: 202-203.

2. Sopena JM, Romero E (2004) Redes neuronales y métodos estadísticos clásicos en el diagnóstico médico: la importancia de las variables irrelevantes. Med Clin (Barc) 122: 336-338.

3. Deleuze G, Guattari F (1984) AntiOedipus: Capitalism and Schizophrenia, University of Minnesota Press, New York, USA.

4. Deleuze G, Guattari F (1988) A Thousand Plateaus, Athlone Press, London.

5. Turabian Jl, Perez FB (2009) The Tree And The Grass: The Mesh Network Of The Clinic In Family Medicine. Influence In Practice And Training.

6. Turabian JL, Perez FB (2006) The Specific Framework of Clinical Practice in Family Medicine: Implications for Practice and Training. Aten Primaria 38: 349-452.

7. Katerndahl DA (2005) Is your practice really that predictable? Nonlinearity principles in family medicine. J Fam Pract 54: 970-977. 